Res., Soc. Dev. 2019; 8(1):e4781636

ISSN 2525-3409 | DOI: http://dx.doi.org/10.33448/rsd-v8i1.636

\title{
Aprendizagem por Projetos no Ensino Fundamental: estratégia para entendimento da pirâmide alimentar
}
Learning for Projects in Fundamental Teaching: strategy for understanding food pyramid

\section{Aprendizaje por Proyectos en la Enseñanza Fundamental: estrategia para entendimiento de la pirámide alimentaria}

\author{
Ana Paula Santos de Lima \\ ORCID: https://orcid.org/0000-0002-1611-8295 \\ Universidade Federal de Santa Maria, Brasil \\ E-mail: aninhalima.sm@gmail.com \\ Phillip Vilanova Ilha \\ ORCID: https://orcid.org/0000-0002-4433-0349 \\ Universidade Federal do Pampa, Brasil \\ E-mail: phillip@unipampa.edu.br \\ Rodrigo Couto Corrêa da Silva \\ Universidade Federal do Rio Grande do Sul, Brasil \\ E-mail: rodrigo.couto@gmail.com \\ Félix Alexandre Antunes Soares \\ ORCID: https://orcid.org/0000-0002-6453-7902 \\ Universidade Federal de Santa Maria, Brasil \\ E-mail: felix@ufsm.br
}

Recebido: 21/09/2018 | Revisado: 19/10/2018 | Aceito: 23/11/2018 | Publicado: 12/12/2018

\section{Resumo}

Este trabalho tem por objetivo avaliar o conhecimento sobre a pirâmide alimentar por ano escolar dos alunos das séries finais do ensino fundamental, assim como, o quanto uma proposta por aprendizagem de projetos pode influenciar na aquisição desses conceitos pelos estudantes. Trata-se de um estudo de caso realizado na cidade de Santa Maria/RS, com escolares do $6^{\circ}$ ao $9^{\circ}$ ano de uma escola estadual pública, totalizando 158 alunos. Os alunos responderam a duas questões sobre como imaginavam ser a pirâmide alimentar. Foram encontradas, em ambas as respostas, um melhor resultado no $6^{\circ}$ e $8^{\circ}$ ano; porém, o entendimento dos alunos do $6^{\circ}$ ano obteve uma melhora acentuada no pós-teste, podendo isso 
indicar que os projetos desenvolvidos pelas professoras nessas duas turmas tenham obtido uma melhor aprendizagem significativa por parte dos alunos.

Palavras-chave: Alimentação; Educação Básica; Estratégias de Ensino; EnsinoAprendizagem.

\begin{abstract}
This study aims to assess the knowledge of the food pyramid for school year the students of final grades of primary school, as well as a proposal for how learning designs can influence the acquisition of these concepts by students. This is a case study in the city of Santa Maria / RS, with students from 6th to 9th grade of a public state school, totaling 158 students. The students answered two questions about the food pyramid be imagined. In both responses, found a better result on the 6th and 8th grade, but students' understanding of the 6th year achieved a marked improvement in post-test, and this could indicate that the projects developed by teachers in these two groups have obtained best meaningful learning by students.
\end{abstract}

Keywords: Food; Basic Education; Teaching Strategies; Teaching-Learning.

\title{
Resumen
}

Este trabajo tiene por objetivo evaluar el conocimiento sobre la pirámide alimentaria por año escolar de los alumnos de las series finales de la enseñanza fundamental, así como, cuánto una propuesta por aprendizaje de proyectos puede influir en la adquisición de esos conceptos por los estudiantes. Se trata de un estudio de caso realizado en la ciudad de Santa Maria / RS, con escolares del $6^{\circ}$ al $9^{\circ}$ año de una escuela estatal pública, totalizando 158 alumnos. Los alumnos respondieron a dos preguntas sobre cómo imaginaban ser la pirámide alimentaria. Se encontraron, en ambas respuestas, un mejor resultado en el $6^{\circ}$ y $8^{\circ}$ año; pero el entendimiento de los alumnos del sexto año obtuvo una mejora acentuada en el post-test, pudiendo eso indicar que los proyectos desarrollados por las profesoras en estas dos clases obtuvieron un mejor aprendizaje significativo por parte de los alumnos.

Palabras clave: Alimentación; Educación básica; Estrategias de Enseñanza; La enseñanza y el aprendizaje.

\section{Introdução}

A questão da alimentação é importante na educação básica e seu estudo pode ajudar as crianças a levar bons padrões ou boas práticas para suas vidas. 
Res., Soc. Dev. 2019; 8(1):e4781636

ISSN 2525-3409 | DOI: http://dx.doi.org/10.33448/rsd-v8i1.636

Ao longo da evolução da humanidade, diferentes dietas foram adotadas pelos povos. Padrões alimentares pertencentes a seu percurso histórico e cultural, além de diversos fatores de influências, como o comércio de especiarias que agregou o caráter gastronômico a alimentação (ABREU et al., 2001).

Este artigo tem como objetivo apresentar uma avaliação do conhecimento sobre a pirâmide alimentar por ano escolar dos alunos das séries finais do ensino fundamental, assim como, o quanto uma proposta por aprendizagem de projetos pode influenciar na aquisição desses conceitos pelos estudantes.

\section{Alguns aspectos históricos relacionados com a alimentação}

No final da década de 1940, os estudos Twin Cities e o Framingham Heart Study, examinaram a correlação entre o aumento de doenças crônicas não transmissíveis e a associação destes com fatores dietéticos, e em 1956, foi publicado o Basic Four, por especialistas em nutrição, com a recomendação de porções de quatro grupos de alimentos a serem consumidos (leite, carnes, vegetais e frutas, pães e cereais). E a partir de 1970, outros estudos começaram a contribuir para a associação entre determinadas doenças e as práticas alimentares (BARBOSA, COSTA \& SOARES, 2006).

Com sucessivas melhorias, a pirâmide alimentar tal como a conhecemos foi constituída, e em 1992 o Departamento de Agricultura dos Estados Unidos e o Brasil passaram a utilizar o modelo desenvolvido pela Organização Pan-Americana de Saúde (OPAS) com participação do Ministério da Saúde em uso desde 2002. Na pesquisa realizada pelos autores Lanzillotti, Couto \& Afonso (2005), abordam o modelo de pirâmide alimentar proposto por Philippi et al (1999) que levam em consideração os hábitos alimentares da população brasileira e propuseram uma organização hierárquica vertical da informação, dividida em quatro níveis: o primeiro nível corresponde ao grupo dos pães, cereais, arroz e massas, com seis a onze porções; o segundo, o grupo das verduras e legumes, com três a cinco porções, e as frutas, com duas a quatro porções; o terceiro nível, grupo do leite, iogurte e queijos, com duas a três porções, e as carnes, aves, peixes, leguminosas, ovos e nozes, com duas a três porções; e o quarto nível, grupo das gorduras, óleos e açúcares, com a recomendação de uso moderado.

Devido as mudanças de hábitos alimentares apresentada pela população brasileira nos últimos anos, o Guia Alimentar para a População Brasileira de 2014, também acompanhou essas mudanças. A abordagem utilizada demonstra uma preocupação para que haja o 
entendimento para que a população se utilize menos de produtos processados (adiciona-se sal ou açúcar a alimentos in natura para torná-los mais agradáveis ao paladar e mais duráveis) e ultraprocessados (utiliza-se de formulações industriais feitas de substâncias extraídas de alimentos ou sintetizadas em laboratórios), aproveitando mais em sua alimentação, alimentos in natura ou minimamente processados (BRASIL, 2014). Tendo em vista a grande quantidade de substâncias que aqueles produtos apresentam, como uma grande quantidade de conservantes, açucares e sal. Dessa forma, a opção pela alimentação de produtos in natura, seria uma opção mais equilibrada e saudável, apresentando uma elevada qualidade nutricional. Assim, conforme Ibid no Guia Alimentar para a População Brasileira torna-se uma ferramenta para orientação a população no sentido de adquirir hábitos mais saudáveis quanto a alimentação.

Vale ainda destacar que, esses alimentos muito processados, contém em grande parte em sua composição, ingredientes que não estão na pirâmide alimentar, assim apresentando baixos níveis de nutrientes e com isso podendo prejudicar o processo de aprendizagem do estudante. Isso porque, pode causar problemas de concentração, atenção, retenção da informação, ocasionando um baixo rendimento escolar (ROLANDO \& JAVIER, 2018)

Reconhece-se a partir das políticas de Estado, exercidas na estratégia de difusão do conhecimento sobre dietas saudáveis como para a promoção da saúde com o uso da pirâmide alimentar. Segundo Lanzillotti et al. (2005), na tentativa de formar hábitos alimentares adequados, justifica-se o uso de guias alimentares, pois os conceitos que envolvem o complexo sistema entre alimentação e nutrição devem promover condições para que ocorram mudanças no comportamento no ato de se alimentar. Por esse motivo, a importância dessa abordagem pelos professores do ensino fundamental neste projeto, possibilitando uma correta orientação para que as mudanças de práticas alimentícias inadequadas se processem no tempo devido, pois é basicamente nesse período que os adolescentes estão gradualmente formando seus hábitos alimentares (BRASIL, 2008).

De acordo com Reyes (2017) ao abordarmos sobre a temática nutrição, é necessário inicialmente compreender quais são os grupos de alimentos, quantas porções devemos consumir de cada grupo, assim como quais são os grupos que devem ser ingeridos diariamente e quais grupos devem ser ingeridos ocasionalmente, tudo isso levando em consideração a prática de atividade física. Por isso, a importância de estudar sobre a pirâmide alimentar e fazer com que os estudantes compreendam da melhor forma possível para que possam aplicá-la em seu cotidiano. Além disso, ainda segundo esta mesma autora, a importância deste entendimento, se reflete diretamente no crescimento e desenvolvimento dos 
indivíduos, tendo em vista uma alimentação adequada e balanceada, a qual resultará em um melhor funcionamento do organismo.

Esta pesquisa buscou atuar no período a partir da escolarização do ensino de ciências nas séries finais do ensino fundamental no cotidiano do sujeito. E o professor pode abordar conteúdos específicos do Ensino de Ciências, identificando seus conhecimentos sobre a pirâmide alimentar. Além disso, promover a autonomia e a capacidade crítica quanto ao conhecimento dos discentes sobre alimentação saudável. Nesse contexto, o professor estará facilitando o processo de ensino-aprendizagem do educando, atuando na identificação de seus conhecimentos prévios através da atividade investigada, ou seja, pelos esclarecimentos decorrentes dela. A atividade passa a auxiliar no processo de construção do conhecimento para que seja significativo (PERONEO, 2008).

A percepção cognitiva dos aprendentes, sob a comunicação simbólico-iconográfica, segundo a visão de Pierce, define que o sistema de significação não estabelece uma verdade, mas uma interpretação próxima da verdade segundo cada observador. (LANZILLOTTI et al., 2005). Ou seja, a pirâmide alimentar, intenta representar as boas práticas através de seu simbolismo gráfico, mesmo sendo um sistema que não é a verdade, mas uma aproximação da verdade, neste caso pode ou não estar atrelada a realidade particular dos leitores de tal símbolo. A pirâmide apenas provoca a reflexão o que exige compreensão além dela mesma, para que possa ser transmitida a informação. Portanto, a pirâmide alimentar é uma interpretação representativa de um conceito predecessor, pois não pode ser corretamente interpretada sem que o código alimentar tenha sido previamente explicado (LANZILLOTTI et al., 2005). O interpretante, a representação (desenhos coletados) e seu objeto (conteúdo) formam a semiose entre as boas práticas alimentares e o signo representado pela pirâmide alimentar, assim sendo, para o leitor a imagem da pirâmide e o seu conteúdo, auxiliarão para que este faça a interpretação ligando-o as boas práticas alimentares.

Ainda que o mesmo modelo referencial sobre dietas alimentares venha sendo utilizado desde a década de 1970, os interpretantes (leigos) não são os intérpretes. Os especialistas são os intérpretes (nesse caso, os pesquisadores) que codificam a comunicação para democratizar a informação na expectativa de que a cognição produza a significação desejada (nos alunos), dessa forma, possibilitando que as pessoas elaborem sua dieta de maneira equilibrada (LANZILLOTTI et al. 2005). Para Piaget (1996), o desenvolvimento é uma cognição contínua, que envolve sujeitos em interação com objetos, portanto o docente pode articular esta interação direcionada a mudança de hábitos. Ao longo da vida, os indivíduos vão organizando e incrementando conceitos que vão sendo aprendidos e o ensino de ciências pode 
contribuir na articulação do saber para a promoção da saúde, auxiliando o fortalecimento para uma melhor alfabetização científica de crianças e adolescentes (PERONEO, 2008).

Essa articulação do novo conhecimento com os conhecimentos prévios dos alunos, possibilitando um encaminhamento pedagógico contextualizado para que o processo de ensino-aprendizagem seja realmente efetivado, pode ser observada na utilização da aprendizagem por projetos, como destacado por Hernández e Ventura (1998):

A função do projeto é favorecer a criação de estratégias de organização dos conhecimentos escolares em relação a: 1) o tratamento da informação, e 2) a relação entre os diferentes conteúdos em torno de problemas ou hipóteses que facilitem aos alunos a construção de seus conhecimentos, a transformação da informação procedente dos diferentes saberes disciplinares em conhecimento próprio (HERNÁNDEZ \& VENTURA, 1998, p 61).

Com isso, o objetivo desta pesquisa foi avaliar o conhecimento sobre a pirâmide alimentar por ano escolar dos alunos das séries finais do ensino fundamental, assim como a influência da metodologia de uma proposta por aprendizagem de projetos na aquisição desses conceitos pelos estudantes.

\section{Procedimentos metodológicos}

Trata-se de um estudo de caso realizado na cidade de Santa Maria, estado do Rio Grande do Sul, com escolares do $6^{\circ}$ ao $9^{\circ}$ ano, de uma escola estadual da rede pública. A amostra total de escolares estudada foi de 158 alunos, sendo que estes fazem parte do projeto "intervenções no ambiente escolar utilizando a promoção da saúde como ferramenta para melhoria do ensino", desenvolvido pelo GENSQ. O estudo foi aprovado pelo Comitê de Ética da Universidade Federal de Santa Maria, sob o número: 23081.004120/2011-90, e todos os participantes ou responsáveis assinaram os termos de consentimento livre e esclarecido conforme a Res. 196/96 do Conselho Nacional de Saúde.

Os questionários relativos às perguntas sobre a pirâmide alimentar foram aplicados aos alunos pelos pesquisadores, dentro das salas de aula. As avaliações ocorreram em um total de oito turmas e realizaram-se em dois momentos no ano letivo, no mês de março, o $1^{\circ}$ teste, e no mês de dezembro, o $2^{\circ}$ teste. Utilizou-se uma pergunta fechada contendo três opções de repostas e uma pergunta aberta relativa ao desenho da pirâmide alimentar. Para categorização 
e consecutiva análise das respostas dos alunos sobre esse desenho, utilizou-se a Teoria Peirciana (2003), por se tratar de uma comunicação simbólico-iconográfica.

O presente estudo objetivou analisar o conhecimento apresentado pelos alunos das séries finais do ensino fundamental sobre a pirâmide alimentar, através das seguintes questões: "Você conhece a pirâmide alimentar?" questão fechada na qual os alunos deveriam marcar apenas uma das três opções: a) Conhece a pirâmide alimentar; b) Não conhece a pirâmide alimentar ou c) Apenas ouviu falar; e a questão aberta "Desenhe como você imagina a pirâmide alimentar". De acordo com o desenho de cada aluno, suas respostas foram enquadradas dentro de seis categorias: Não desenhou ou desenhou erradamente; Pirâmide com apenas as divisões; Pirâmide com divisões e representação de alimentos; Pirâmide com alimentos invertidos ou local errado; Pirâmide com grupos e divisões corretos; Pirâmide totalmente correta com alimentos corretos. Também foi mensurada a influência da metodologia de uma proposta por aprendizagem de projetos na aquisição desses conceitos pelos alunos.

Para que fosse possível implementar essa proposta por aprendizagem de projetos, através de intervenções colaborativas, os professores passaram por uma formação continuada ao longo do ano letivo, desenvolvida pelo grupo GENSQ, sendo composto por alunos do Programa de Pós-Graduação Educação em Ciências: Química da Vida e Saúde, da Universidade Federal de Santa Maria, dividida em três momentos: reflexões das atividades desenvolvidas no ano anterior; aprofundamento teórico que ocorreu no decorrer de todo o ano e a elaboração e o desenvolvimento de projetos pedagógicos, de abril a novembro. $\mathrm{O}$ programa contou com a participação de 12 professores, sendo 01 professor de Geografia, 01 de Português, 02 de Ciências, 01 de Ensino Religioso, 01 de Educação Física, 02 de Língua Estrangeira, 01 de Artes, 01 de História e 02 de Matemática. Para constatar as percepções dos professores, utilizou-se entrevista semiestruturada, diário de campo e de observação do participante. A entrevista com os docentes foi constituída por questões sobre as estratégias pedagógicas utilizadas e as dificuldades encontradas na aplicação da proposta.

Foi utilizada a análise descritiva para calcular as frequências das variáveis. Para calcular a diferença entre a primeira e a segunda avaliação, aplicou-se o teste de Wilcoxon. O nível de significância foi de $5 \%$.

\section{Resultados e discussão}


As tabelas a seguir apresentam a distribuição do número de alunos no $1^{\circ}$ e $2^{\circ}$ testes quanto às questões: Você conhece a pirâmide alimentar? (Tabela 1) e Desenhe como você imagina a pirâmide alimentar (Tabela 2). Lembrando que o total de entrevistados foi de 158 alunos, sendo $50,6 \%$ do sexo feminino e $49,4 \%$ do sexo masculino.

Em um primeiro momento, foi perguntado aos alunos se eles conheciam a pirâmide alimentar. De acordo com as respostas dadas pelos alunos, percebeu-se que, de maneira geral, a maioria destes conhece a pirâmide alimentar, sendo que esse total no pré-teste era de 59,5\% e no pós-teste passou para 78,2\%. Esse resultado corrobora com os estudos que mostram que a pirâmide alimentar vem sendo fortemente difundida para a população brasileira nos últimos anos (LANZILLOTTI et al., 2005).

A análise estatística para a pergunta "Você conhece a pirâmide alimentar?" mostrou significância para o $6^{\circ}$ e o $8^{\circ}$ ano escolar, sendo mais acentuado para o sexto ano, conforme observado na Tabela 1.

Tabela 1 - Resposta dos alunos referente à pergunta "Você conhece a pirâmide alimentar?".

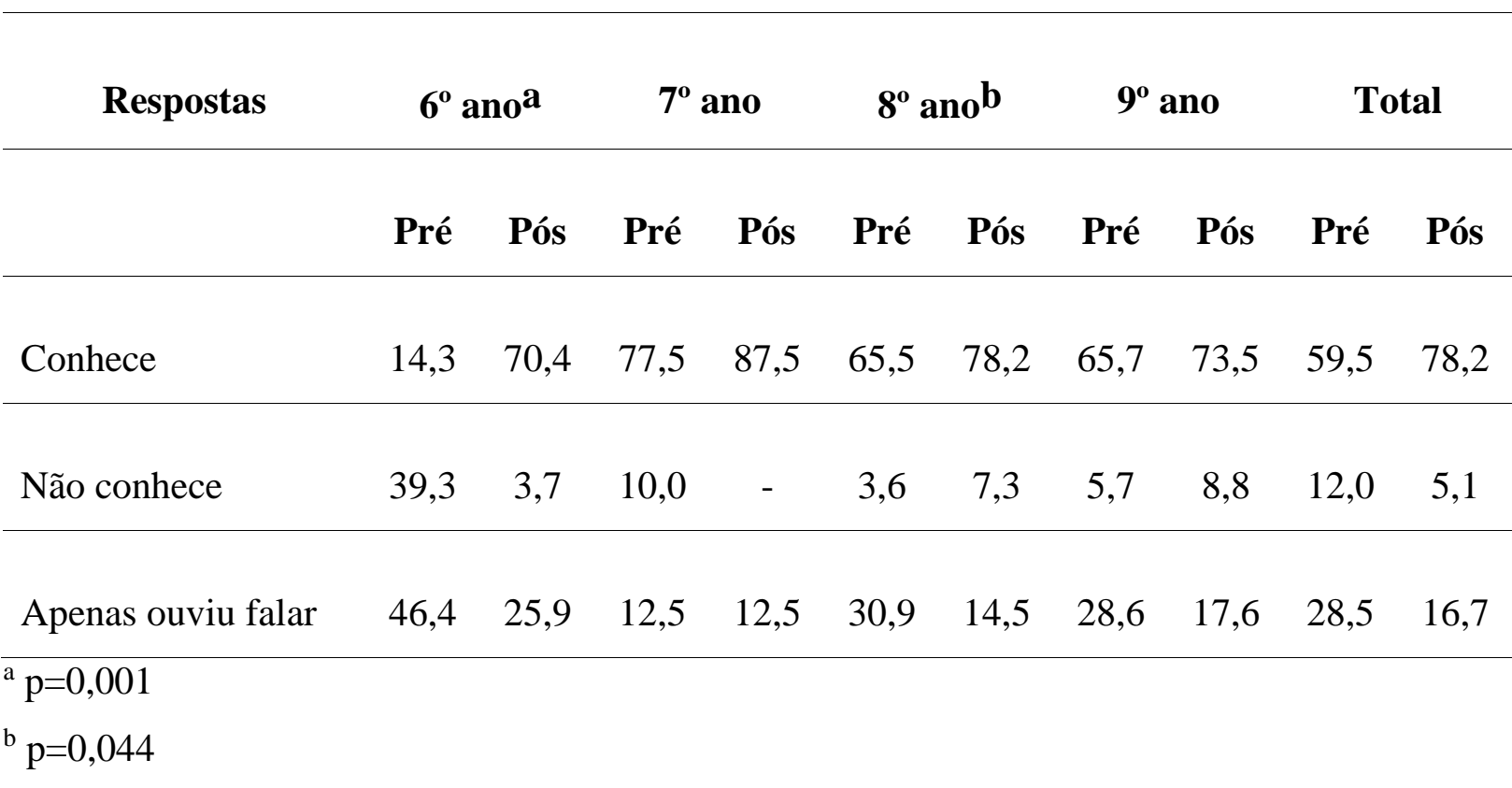

Fonte: Elaborado pelos autores

Através dessa análise, é possível observar o aumento do número de alunos que responderam conhecer a pirâmide alimentar no pós-teste, como verificado principalmente no $6^{\circ}$ ano. Já no pré-teste o número de alunos que diziam conhecer a pirâmide foi de $14,3 \%$, e esse número intensifica-se acentuadamente no pós-teste para 70,4\%. Isso foi devido à grande redução do número de estudantes que haviam marcado as opções "Não conhece" e "Apenas 
ouviu falar" referentes a esse assunto.

Na Tabela 2, encontram-se os resultados comparativos do $1^{\circ}$ e $2^{\circ}$ teste para as frequências das categorias das respostas referentes à pergunta sobre o desenho da pirâmide alimentar, analisada separadamente por ano escolar.

Tabela 2 - Frequência das categorias dos desenhos da pirâmide alimentar por ano escolar relativa a março (pré) e dezembro (pós).

\begin{tabular}{|c|c|c|c|c|c|c|c|c|c|c|}
\hline \multirow[t]{2}{*}{ Respostas } & \multicolumn{2}{|c|}{$6^{0}$ ano $^{a}$} & \multicolumn{2}{|c|}{$7^{\circ}$ ano } & \multicolumn{2}{|c|}{$8^{o}$ ano $^{b}$} & \multicolumn{2}{|c|}{$9^{\circ}$ ano } & \multicolumn{2}{|c|}{ Total } \\
\hline & Pré & Pós & Pré & Pós & Pré & Pós & Pré & Pós & Pré & Pós \\
\hline $\begin{array}{l}\text { Não desenhou ou } \\
\text { erradamente }\end{array}$ & 71,4 & 25,0 & 17,5 & 12,5 & 10,9 & 27,3 & 14,3 & 40,0 & 24,1 & 25,9 \\
\hline $\begin{array}{l}\text { Apenas com } \\
\text { divisões }\end{array}$ & 10,7 & 25,0 & 25,0 & 50,0 & 43,6 & 45,5 & 48,6 & 42,9 & 34,2 & 42,4 \\
\hline $\begin{array}{l}\text { Representações de } \\
\text { alimentos }\end{array}$ & 14,3 & 42,9 & 47,5 & 32,5 & 16,4 & 14,5 & 28,6 & 8,6 & 26,6 & 22,8 \\
\hline $\begin{array}{l}\text { Alimentos } \\
\text { invertidos ou } \\
\text { trocados }\end{array}$ & 3,6 & 7,1 & 10,0 & 5,0 & 27,3 & 3,6 & 8,6 & 5,7 & 14,6 & 5,1 \\
\hline $\begin{array}{l}\text { Grupos e divisões } \\
\text { corretos }\end{array}$ & - & - & - & - & 1,8 & 9,1 & - & - & 0,6 & 3,2 \\
\hline Totalmente correta & - & - & - & - & - & - & - & 2,9 & - & 0,6 \\
\hline
\end{tabular}

Fonte: Elaborado pelos autores

Considerando as respostas dos alunos sobre essa questão, é possível observar a diferença entre as variáveis do desenho da pirâmide alimentar relativas a março e dezembro; a pontuação de dezembro, no $6^{\circ}$ ano, que é significativamente maior do que em março, apresentando um p=0,002, no $8^{\circ}$ ano, ocorre justamente o oposto, com um $\mathrm{p}=0,024$, e no $7^{\circ}$ e $9^{\circ}$ ano não houve essa diferença.

Através das análises dos dados, conforme observado na tabela anterior, de maneira geral, houve um melhor entendimento em relação ao desenho da pirâmide alimentar. Quanto à categoria "Não desenhou ou desenhou erradamente", é possível verificar uma diminuição 
acentuada dessas respostas em dezembro (25\%), se comparado a março $(71,4 \%)$, nos $6^{\circ}$ anos, no $7^{\circ}$ ano houve também uma redução, mas não tão expressiva como ocorreu nos $6^{\circ}$ anos. Porém, nos $8^{\circ}$ e $9^{\circ}$ anos, o número de alunos que "Não desenhou" ou "Desenhou erradamente" aumentou no mês de dezembro, conforme demonstra a Tabela 2. Ocorreu aumento também, em dezembro, em todos os anos escolares em relação à categoria "Pirâmide com apenas as divisões", isso demonstra que os alunos entendem que há divisões dentro da pirâmide alimentar. No $6^{\circ}$ ano, no mês de março, o número de alunos que tinha esse entendimento era de 10,7\%, em dezembro passou para $25 \%$ dos alunos. Já essa compreensão no $7^{\circ}$ ano em março era de $25 \%$, passando em dezembro para $50 \%$ dos alunos que possuem esse significado.

Ao verificar o grupo de respostas "Pirâmide com divisões e representação de alimentos", é possível observar um relevante aumento nesta categoria de março (14,3\%) para dezembro (42,9\%), nas respostas dos alunos do $6^{\circ}$ ano que se enquadraram nesse grupo. Isso possibilita verificar que esses alunos, no decorrer do ano, adquiriram conhecimento suficiente para saber que há grupos específicos de alimentos distribuídos em categorias dentro da pirâmide alimentar. Nos demais anos, $7^{\circ}, 8^{\circ}$ e $9^{\circ}$, houve uma drástica redução em dezembro para esse quesito (conforme demonstra a Tabela 2).

Para o item "Pirâmide com alimentos invertidos ou local errado", observa-se uma redução dos valores nos $7^{\circ}, 8^{\circ}$ e $9^{\circ}$ anos, sendo mais acentuado para o $8^{\circ}$ ano, no qual esse valor foi de $27,3 \%$, passando em dezembro para 3,6\%. No entanto, na segunda avaliação do $6^{\circ}$ ano, houve um aumento referente a essa categoria, demonstrando uma leve confusão de alguns alunos relativa aos grupos de alimentos.

Para a categoria "Pirâmide com grupo e divisões corretos", as respostas encontradas, somente o $8^{\circ}$ ano foi possível verificar progresso nas respostas quanto a essa questão, sendo que em março esse número foi de 1,8\%, alterando-se para 9,1\% em dezembro. O último grupo de respostas foi "Pirâmide totalmente correta com alimentos corretos, para este item obtivemos respostas somente em dezembro (2,9\%) sendo apenas dos estudantes do $9^{\circ}$ ano.

Ao analisar os livros didáticos de ciências adotados pela escola, para averiguar em que ano letivo o conteúdo de pirâmides alimentares é abordado pelos professores. Observou-se que os conteúdos abordados em cada ano letivo se organizam na seguinte proposta pedagógica: $6^{\circ}$ ano - meio ambiente como um todo; $7^{\circ}$ ano - os seres vivos e suas classificações; $8^{\circ}$ ano - corpo humano, no qual o capítulo "Alimentação Saudável” trabalha com a composição da pirâmide alimentar; e $9^{\circ}$ ano - conteúdos de química e física.

Contudo, após analisar os dados da Tabela 2, é possível observar que, apesar desse 
assunto ser tratado pelos professores no $8^{\circ}$ ano, a maioria dos alunos não apresentam um bom entendimento sobre a composição da pirâmide alimentar. Os dados demonstram que esse conhecimento piorou ao longo do ano letivo, ou seja, segundo os dados de março, os alunos possuíam uma melhor compreensão antes deste conteúdo ser trabalhado pelos professores. No entanto, os alunos que obtiveram uma melhor evolução no decorrer do ano letivo na compreensão desse tema foram os alunos do $6^{\circ}$ ano; porém, esse assunto não consta nos conteúdos que normalmente seriam abordados pelos professores durante o ano letivo em questão.

Podemos inferir que esse resultado pode ter sido obtido devido ao fato de os professores terem participado de uma formação continuada no decorrer do ano letivo, na qual os pesquisadores trabalharam através de intervenções colaborativas juntamente com os docentes na implementação de uma proposta por aprendizagem de projetos abordando temas relacionados à promoção da saúde, por exemplo: hábitos alimentares, conhecimento nutricional, alimentação saudável, atividade física e imagem corporal. Com esses temas, após a formação, os professores deveriam elaborar projetos para trabalharem com seus alunos. As intervenções colaborativas visaram transformar as práticas vigentes dos professores por meio da formação crítica e reflexiva sobre as práticas pedagógicas, sendo elaboradas, juntamente com os gestores e professores participantes, durante o transcorrer da pesquisa.

Apesar de todos os professores terem participado da formação, os projetos que eles desenvolveram em cada ano escolar foi diferente, o que pode ter resultado nessa diferença de conhecimento sobre a pirâmide alimentar, conforme observamos nas respostas dos estudantes. Dessa forma, podemos dizer que o projeto desenvolvido no $6^{\circ}$ ano instigou mais os alunos para a pesquisa e na construção desse conhecimento referente a este tema, fazendo com que os conceitos se tornassem relevantes para a estrutura cognitiva do aluno e com isso facilitando o processo de aprendizagem, sendo que esse assunto foi abordado por todos os professores responsáveis por este projeto. Porém, no $8^{\circ}$ ano a abordagem da pirâmide alimentar limitou-se a disciplina de ciências, sendo que o principal enfoque da proposta elaborada pelos professores ficou restrita sobre quais alimentos seriam mais saudáveis ou não para alimentação. Contudo, se o período de aplicação desses projetos ocorresse por um período mais longo, os resultados obtidos poderiam ser melhores, assim como o progresso do conhecimento dos alunos.

Segundo Soares et al. (2017), de acordo com a pesquisa realizada, os escolares citaram que os professores são a segunda fonte principal de informações sobre alimentação, ficando logo após os pais. Isso demostra o papel fundamental da escola e professores, para melhor 
orientar estes escolares sobre este assunto, assim como no comportamento alimentar e no estilo de vida destes. A autora ainda destaca que, para que as mudanças sejam efetivas nos hábitos alimentares destes escolares, é necessário que seja criado um ambiente favorável na escola, para que eles possam ter acesso tanto as informações, quanto aos alimentos em si e a quantidade e variedade adequada destes alimentos. Através dos projetos desenvolvidos pelas professoras, na escola da presente pesquisa, foi possível criar este ambiente, assim como envolver as famílias nesse processo.

Com base na entrevista, no diário de campo e na observação participante, obtivemos os seguintes grupos de trabalho elaborados pelas professoras, em cada ano escolar, para aplicarem em seus projetos, como explanado no Quadro 1.

Os projetos desenvolvidos pelas professoras, como relatado no Quadro 1, está de acordo com Araújo (2003, p. 48), que diz que "as disciplinas curriculares são o eixo vertebrador do sistema educacional e as temáticas transversais às atravessam". Assim, mantendo o papel secundário dos temas transversais no currículo, se comparado aos conteúdos tradicionais de escola.

Quadro 1 - Quadro informativo sobre os projetos desenvolvidos em cada ano escolar pelas professoras.

\begin{tabular}{|c|l|}
\hline Ano escolar & \multicolumn{1}{|c|}{ Grupo de professoras e projetos desenvolvidos } \\
\hline \multirow{2}{*}{$6^{\circ}$ ano } & $\begin{array}{l}\text { Geografia, ed. física, religião e português - atividade física e lazer } \\
\text { desenvolvido pela comunidade escolar - criação de questionários pelos } \\
\text { alunos para aplicação com suas famílias, após levantamento desses dados } \\
\text { através de gráficos sobre a comunidade estudada quanto a atividade física e o } \\
\text { lazer. Elaboração de cartazes com mensagens de conscientização sobre } \\
\text { alimentação saudável, importância da atividade física e construção de } \\
\text { pirâmides alimentares. Caminhada pelo bairro onde os estudantes fizeram } \\
\text { panfletagem sobre essas mensagens com os moradores. Construção de } \\
\text { histórias em quadrinho sobre alimentação saudável pelos alunos. }\end{array}$ \\
\hline \multirow{2}{*}{ ano } & $\begin{array}{l}\text { História, inglês e matemática - discussão da pirâmide alimentar em } \\
\text { diferentes contextos sociais e regiões, construção de recordatórios } \\
\text { alimentares e elaboração de cardápios pelos alunos com objetivo de analisar } \\
\text { suas práticas alimentares. Produção de cartazes sobre alimentação saudável e } \\
\text { de tabelas com valores de peso, massa corporal e cálculo de índice de massa }\end{array}$ \\
\hline
\end{tabular}




\begin{tabular}{|c|l|}
\hline \multirow{3}{*}{$8^{\circ}$ ano } & $\begin{array}{l}\text { corporal (IMC). } \\
\text { (2 turmas) } \\
\text { alimentos saudáveis e não saudáveis com discussão da pirâmide alimentar. } \\
\text { Construção de tabelas e debate de textos sobre alimentos. Criação de um } \\
\text { vídeo pelos alunos sobre alimentação saudável abordando a tema obesidade. }\end{array}$ \\
\hline \multirow{3}{*}{$9^{\circ}$ ano } & $\begin{array}{l}\text { Inglês, literatura e espanhol - utilização do documentário Super Size Me } \\
\text { (dieta de } 30 \text { dias com consumo exclusivo de alimentos do McDonald's) com } \\
\text { posterior discussão sobre essa dieta, elaboração de uma coreografia com uma } \\
\text { música da cantora Beyonce que aborda o tema alimentação. Abordagem } \\
\text { sobre cirurgias plásticas através de poemas e acompanhamento do hábito } \\
\text { alimentar das famílias dos alunos com desenvolvimento de questionários, } \\
\text { pesquisas na internet, revistas e jornais sobre alimentação e esporte para a } \\
\text { construção de um mural com todas essas informações. }\end{array}$ \\
\hline
\end{tabular}

Fonte: Elaborado pelos autores

Através dessa sondagem dos projetos trabalhados pelas professoras em cada ano letivo (Quadro 1), é possível observar que o projeto desenvolvido com o $6^{\circ}$ ano instigou mais os alunos a pesquisar, participar e se envolver na construção do conhecimento, auxiliando no processo de ensino-aprendizagem, pois os conteúdos programáticos deixaram de ser um fim em si mesmo e passam a fazer parte de um todo. Assim, os temas emergentes acabam formando a base do desenvolvimento educacional intelectual. Já no $8^{\circ}$ ano, percebe-se que a abordagem sobre a pirâmide alimentar foi mais pontual, ficando restrita ao conteúdo dentro da disciplina de ciências. O livro adotado pela escola traz o desenho de três pirâmides alimentares: uma latino-americana, uma mediterrânea e uma asiática, sem muitas considerações sobre o motivo de suas divisões e recomendações de consumo diário de porções, nem sobre a formação dos grupos de alimentos.

A expectativa lógica seria que os alunos do $8^{\circ}$ ano, no qual o conteúdo de pirâmide alimentar faz parte, demonstrassem maior entendimento quanto ao desenho da pirâmide alimentar. Porém, o que aconteceu foi que esse entendimento diminuiu no decorrer do ano, como observado na Tabela 2. De acordo com Pelizzari et al (2002), conforme o novo conteúdo é assimilado ao conhecimento prévio dos alunos, maior é o significado adquirido, ou seja, mais significativa é a aprendizagem. Quando essa assimilação não acontece, ocorre aprendizagem mecânica ou repetitiva, situação em que os alunos decoram os conteúdos sendo esquecidos logo após a avaliação. Moreira (2008) apud Ausubel (1982) descreve que a 
aprendizagem mecânica seria a aprendizagem de novas informações com pouca ou nenhuma relação com conceitos relevantes existentes na estrutura cognitiva.

Segundo Moreira (2011), a aprendizagem significativa por definição, para David Ausubel, envolve aquisição/construção de significados, pois é no curso da aprendizagem significativa que o significado lógico dos materiais de aprendizagem se transforma em significado psicológico para o aprendiz, sendo que a estrutura cognitiva tende a organizar-se hierarquicamente em termos de nível de abstração, generalidade e inclusividade de seus conteúdos.

Constata-se que a maioria dos alunos apresentou maior interesse com nas aulas desenvolvidas através da aprendizagem por projetos. Esses resultados reforçam a ideia de Nogueira (2006), em que o educando passa a se interessar mais pela aula quando o ensino passa a ter significado para o aluno, assim sendo, quando ele aprende no processo de produzir, de levantar dúvidas, de pesquisar e de criar relações, que incentivam novas buscas, descobertas, compreensões e reconstruções de conhecimentos.

O trabalho com projetos apresenta uma natureza investigativa, sendo possível ir além da fragmentação disciplinar, pelo fato de ser complementar ao saber e não às disciplinas. Ao trabalhar com essa metodologia na construção do conhecimento escolar, a prática pedagógica é enriquecida, pois os alunos são instigados a pesquisar, saber trabalhar em grupo, pensar de modo autônomo, expressar-se em público e, além disso, ver a abordagem do conhecimento como uma rede de significados (OLIVEIRA \& MOURA, 2005).

Nesse sentido, averiguou-se que os projetos de aprendizagem estimularam os escolares a melhorar o seu conhecimento sobre a pirâmide alimentar, especialmente no $6^{\circ}$ ano. Segundo Oliveira (2006), o trabalho com projetos aproxima alunos e professores, dinamizando o processo educativo na articulação de seus atores, como constituintes ativos na construção do conhecimento. O mesmo autor descreve que o relato das escolas tem sido proveitoso na abordagem de conteúdos atitudinais e procedimentais e no desenvolvimento das inteligências múltiplas na prática do trabalho com projetos.

\section{Considerações finais}

Através da aprendizagem por projetos, foi possível que as professoras trabalhassem com maior ênfase sobre a pirâmide alimentar em sala de aula. Essa estratégia mostrou-se muito eficaz pelo fato de o aluno participar de maneira mais colaborativa em sala de aula, o que resultou em uma melhor aprendizagem. Por meio desta abordagem, as docentes puderam 
discutir com os alunos sobre a educação nutricional e assim os capacitando para que possam agir de forma mais consciente sobre a questão alimentar e com isso possibilitando formar bons hábitos alimentares desde a infância.

Este trabalho teve como objetivo avaliar o conhecimento sobre a pirâmide alimentar por ano escolar dos alunos das séries finais do ensino fundamental, assim como a influência da metodologia de uma proposta por aprendizagem de projetos na aquisição desses conceitos pelos estudantes. Com a análise dos resultados obtidos, pôde-se verificar que a intervenção por aprendizagem de projetos trouxe colaborações significativas nas duas turmas de $6^{\circ}$ ano quanto às duas questões que envolviam a pirâmide alimentar. Isso porque, através dos projetos de aprendizagem desenvolvidos pelas professoras, os alunos puderam construir seu conhecimento de forma colaborativa e o professor agiu como mediador da aprendizagem. Já quando ocorreu a centralidade do processo ensino-aprendizagem pelo professor, a percepção de motivação e aprendizado é menor.

Também foi possível averiguar que os resultados dos testes demonstraram grandes variações, antes e após a aplicação da oficina. Acredita-se que o curto período de tempo em que a dinâmica foi estabelecida não foi suficiente para ocasionar ou influenciar uma mudança nos hábitos alimentares dos estudantes, sendo necessário um período maior de tempo, para que tais mudanças fossem alcançadas. Contudo, todas as pequenas variações investigadas no comportamento alimentar dos alunos, em decorrência das oficinas, permitiram afirmar que o método é capaz de promover saúde e alimentação nas escolas de forma eficiente. Sendo assim, é possível tornar o processo de ensino-aprendizagem mais fácil e prazeroso, tanto para os alunos quanto para o professor.

A prática da aprendizagem por projetos possibilita aos alunos adquirirem autonomia diante das situações propostas pelos professores, melhorarem a criatividade na resolução de problemas, assim como trabalharem em equipe. Além disso, aproxima professor e alunos, possibilitando que cada aluno construa seu conhecimento. Com isso, os resultados obtidos neste trabalho apontam positivamente para o trabalho com a metodologia para a aprendizagem por projetos, mostrando-se uma ferramenta eficaz no processo de ensinoaprendizagem.

Mais estudos sobre este assunto devem ser estimulados, pois a temática é de extrema importância tendo em vista a epidemia mundial de obesidade em todas as faixas etárias da população. E ao priorizar conteúdos como este em sala de aula, poderá auxiliar para que os estudantes venham a tomar melhores decisões quanto a sua alimentação, podendo também influenciar na rotina alimentar da família. 


\section{Referências}

ABREU, E. S. et al. Alimentação mundial - uma reflexão sobre a história. Revista Saúde e Sociedade, São Paulo, v.10, n.2, p. 3-14, 2001. Disponível em:<http://www.scielo.br/scielo.php?script=sci_arttextHYPERLINK"http://www.scielo.br/sci elo.php?script=sci_arttext\&pid=S0104-12902001000200002"\&HYPERLINK

"http://www.scielo.br/scielo.php?script=sci_arttext\&pid=S0104-

12902001000200002"pid=S0104-12902001000200002>. Acesso em: 17 abril de 2018.

ARAÚJO, U. F. Temas Transversais e a Estratégia de Projetos. São Paulo: Moderna, 2003.

BARBOSA, R. M. S., COSTA, R. S., \& SOARES, E. A. Guias alimentares para crianças: aspectos históricos e evolução. Revista de Nutrição, Campinas, v.19, n.2, p.255-263, 2006.

Disponível em: $\quad$ http://www.scielo.br/scielo.php?pid=S141552732006000200012HYPERLINK "http://www.scielo.br/scielo.php?pid=S1415-

52732006000200012\&script=sci_abstract\&tlng=pt"\&HYPERLINK"http://www.scielo.br/scie lo.php?pid=S1415-

$\underline{52732006000200012 \& s c r i p t=s c i \_a b s t r a c t \& t \operatorname{lng}=p t " s c r i p t=s c i \_a b s t r a c t H Y P E R L I N K}$

"http://www.scielo.br/scielo.php?pid=S1415-

$\underline{52732006000200012 \& s c r i p t=s c i \_a b s t r a c t \& t \operatorname{lng}=p t " \& H Y P E R L I N K}$

"http://www.scielo.br/scielo.php?pid=S1415-

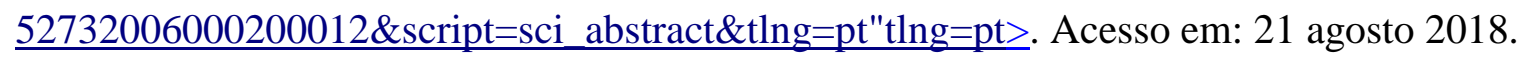

BRASIL. Guia alimentar para a população brasileira: promovendo a alimentação saudável. Ministério da saúde. Brasília, Distrito Federal, Brasil, 2008. Disponível em: 〈http://bvsms.saude.gov.br/bvs/publicacoes/guia_alimentar_populacao_brasileira_2008.pdf $>$. Acesso em: 05 julho de 2018.

BRASIL. Guia alimentar para a população brasileira. (2a ed.) Ministério da Saúde. Brasília, Distrito Federal, Brasil, 2014. Disponível em: $\langle\underline{\text { http://bvsms.saude.gov.br/bvs/publicacoes/guia_alimentar_populacao_brasileira_2ed.pdf }>}$. Acesso em: 08 julho de 2018. 
HERNANDEZ. F., \& VENTURA, M. A Organização do Currículo por Projetos de Trabalho: o conhecimento é um caleidoscópio. Porto Alegre: Artes Médicas, 1998.

LANZILlOTTI, H. S.; COUTO, S. R. M. \& AFONSO, F. M. Pirâmides alimentares: uma leitura semiótica. Revista de Nutrição, Campinas, v.18, n.6, p. 785-792, 2005. Disponível em: <http://www.scielo.br/scielo.php?pid=S1415-

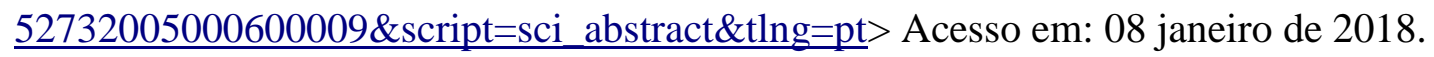

MOREIRA, M. A. A organizadores prévios e aprendizagem significativa. Revista Chilena de Educación Científica, Santiago, v.7, n.2, p. 23-30, 2008. Disponível em: <https://www.if.ufrgs.br/ moreira/ORGANIZADORESport.pdf>. Acesso em: 05 janeiro de 2018.

MOREIRA, M. A. Aprendizagem significativa: um conceito subjacente. Aprendizagem Significativa em Revista/Meaningful Learning Review, Porto Alegre, v.1, n.3, p.25-46, 2011. Disponível em: 〈http://www.if.ufrgs.br/asr/artigos/Artigo_ID16/v1_n3_a2011.pdf>. Acesso em: 10 janeiro de 2018.

NOGUEIRA, N. R. Pedagogia dos Projetos: etapas, papéis e atores. (2a ed.) São Paulo: Editora Érica, 2006.

OLIVEIRA, C. L.; \& MOURA, D. G. de. Metodologia de projetos em ambientes não formais de aprendizagem: indício de eficácia no processo de ensino de biologia. In: V ENCONTRO NACIONAL DE PESQUISA EM EDUCAÇÃO EM CIÊNCIAS. Anais V ENPEC. Bauru, São Paulo: 2005. Disponível em:<http://www.nutes.ufrj.br/abrapec/venpec/conteudo/artigos/3/pdf/p76.pdf>. Acesso em: 28 março de 2018.

OLIVEIRA, C. L. Significado e contribuições da afetividade, no contexto da Metodologia de Projetos, na Educação Básica. 2006. Dissertação (Mestrado em Educação Tecnológica). CEFET-MG. Belo Horizonte, MG, Brasil. Disponível em: <http://www.tecnologiadeprojetos.com.br/banco_objetos/\%7B28A0E37E-294A-4107-906C914B445E1A40\%7D_pedagogia-metodologia.pdf>. Acesso em: 05 março de 2018. 
PEIRCE, C. S. Semiótica. São Paulo: Perspectiva, 2003.

PELIZZARI, A. et al. Teoria da aprendizagem significativa segundo Ausubel. Revista PEC, Curitiba, v.2, n.1, p. 29-42, 2002.

PERONEO, D. S. Algumas reflexões sobre o ensino e a aprendizagem de ciências nos anos iniciais. 2008. Dissertação (Mestrado em Educação em Ciências) - Instituto de Ciências Básicas da Saúde. Programa de Pós-Graduação em Educação em Ciências: Química da Vida e Saúde. Universidade Federal do Rio Grande do Sul. Porto Alegre, RS, Brasil. Disponível em: <https://www.lume.ufrgs.br/bitstream/handle/10183/13858/000655918.pdf?sequence=1 >.

Acesso em: 15 março de 2018.

PHILIPPI, S. T. et al. Pirâmide alimentar adaptada: guia para escolha dos alimentos. Rev. nutr., campinas, v.12, n.1, p. 65-80, 1999. Disponível em: <http://www.scielo.br/pdf/rn/v12n1/v12n1a06.pdf $>$. Acesso em: 21 julho de 2018.

PIAGET, J. Biologia e Conhecimento. (2a ed.) Petrópolis: Vozes, 1996.

REYES, J. A. C. El factor nutricional en el desempeño escolar. Diseño de campaña informativa. 2017. 152 f. Trabalho de Conclusão de Curso - Universid de Guayaquil. Guayaquil, Equador. Disponível em: <http://repositorio.ug.edu.ec/handle/redug/30134>. Acesso em: 29 out. de 2018.

ROLANDO, B. Y. E.; JAVIER, C. G. M. La alimentación y el proceso de aprendizaje. 2018. 82 f. Trabalho de Conclusão de Curso - Universidad Técnica de Cotopaxi. Latacunga. Equador. Disponível em: <http://repositorio.utc.edu.ec/bitstream/27000/4460/1/PI000610.pdf>. Acesso em: 30 out. de 2018.

SOARES, B. R. et al. Atitudes relativas ao consumo alimentar de escolares da zona sul de São Paulo/SP. Disciplinarum Scientia. Santa Maria, v. 18, n. 2, p. 323-337, 2017. Disponível em: <https://www.periodicos.unifra.br/index.php/disciplinarumS/article/view/2100>. Acesso em: 29 out. de 2018. 